\title{
Development of indicators for patient-centred cancer care
}

\author{
Mariëlle Ouwens • Rosella Hermens • Marlies Hulscher • Saskia Vonk-Okhuijsen • \\ Vivianne Tjan-Heijnen • René Termeer • Henri Marres • Hub Wollersheim • \\ Richard Grol
}

Received: 15 September 2008 / Accepted: 2 April 2009/Published online: 23 April 2009

(C) The Author(s) 2009. This article is published with open access at Springerlink.com

\begin{abstract}
Purpose Assessment of current practice with a valid set of indicators is the key to successfully improving the quality of patient-centred care. For improvement purposes, we developed indicators of patient-centred cancer care and tested them on a population of patients with non-small cell lung cancer (NSCLC). Methods Recommendations for patient-centred care were extracted from clinical guidelines, and patients were
\end{abstract}

Radboud University Nijmegen Medical Centre, The Netherlands.

East Comprehensive Cancer Centre, Nijmegen, The Netherlands.

M. Ouwens $\cdot$ R. Hermens $\cdot$ M. Hulscher $\cdot$ H. Wollersheim •

R. Grol

Scientific Institute for Quality of Healthcare (IQ healthcare),

Radboud University Nijmegen Medical Centre,

Nijmegen, The Netherlands

S. Vonk-Okhuijsen

East Comprehensive Cancer Centre,

Nijmegen, The Netherlands

V. Tjan-Heijnen

Division of Medical Oncology, Department of Internal Medicine,

Maastricht University Hospital,

Maastricht, The Netherlands

R. Termeer

Department of Pulmonology, Canisius Wilhelmina Hospital,

Nijmegen, The Netherlands

H. Marres

Department of Otorhinolaryngology, Head and Neck Surgery,

Radboud University Nijmegen Medical Centre,

Nijmegen, The Netherlands

M. Ouwens $(\square)$

Scientific Institute for Quality of Healthcare, 114 IQ healthcare,

Radboud University Nijmegen Medical Centre,

P.O. Box 9101, 6500 HB Nijmegen, The Netherlands

e-mail: M.Ouwens@iq.umcn.nl interviewed to develop indicators for assessing the patientcentredness of cancer care. These indicators were tested with regard to psychometric characteristics (room for improvement, applicability, discriminating capacity and reliability) on 132 patients with NSCLC treated in six hospitals in the east Netherlands. Data were collected from patients by means of questionnaires.

Results Eight domains of patient-centred cancer care were extracted from 61 oncology guidelines and 37 patient interviews and were translated into 56 indicators. The practice test amongst patients with NSCLC showed the most room for improvement within the domains 'emotional and psychosocial support', 'physical support' and 'information supply'. Overall, 26 of the 56 indicators had good psychometric characteristics.

Conclusions Developing a valid set of patient-centred indicators is a first step towards improving the patient centredness of cancer care. Indicators can be based on recommendations from guidelines, but adding patient opinions leads to a more complete picture of patient centredness. The practice test on patients with NSCLC showed that the patient centredness of cancer care can be improved. Our set of indicators may also be useful for future quality assessments for other patients with cancers or chronic diseases.

Keywords Cancer - Oncology · Quality indicators . Health care · Patient-centred care - Quality of health care

\section{Introduction}

As a cause of death in the USA and Europe, cancer is exceeded only by cardiovascular disease [2]. Earlier diagnosis, improved treatment modalities and enhanced supportive care result in cancer taking on the characteristics of a chronic disease more and more [32]. The management of care for 
cancer patients is complex. First, cancer has a very significant impact on the patient's physical, emotional and social wellbeing. Second, various professionals are involved in prevention, diagnosis, treatment and follow-up. This complexity can lead to suboptimal care and result in discontinuity and fragmentation of care $[1,20,24]$. Therefore, there is a need to organise health care delivery in a way that is more patient centred and not disease or provider centred. Patient centredness means that care is organised around the physical, social and emotional needs and preferences of patients and that patients are actively involved in their own care $[25,36]$.

Literature shows that the patient centredness of cancer care can be improved in several ways, such as more supportive care, better communication, better information supply and better cooperation amongst physicians $[23,30$, 35]. To improve the quality of the patient centredness of care for patients with cancer, current practice needs to be reliably assessed [15]. However, this assessment is not straightforward, and selecting appropriate indicators to assess care is difficult. Evidence-based clinical guidelines for the management of patients with cancer can provide recommendations for patient-centred care. The available recommendations from these guidelines should be combined with opinions of the patients themselves so that we can assess additional aspects for which evidence alone is insufficient or absent [18]. To measure the quality of patient centredness, 'patientcentred' recommendations in these guidelines need to be translated into so-called quality indicators. Quality indicators are 'measurable elements of practice performance for which there is evidence or consensus that they can be used to assess the quality of care' [8]. There are some well-known instruments for measuring patient satisfaction $[3,4]$ and patients' experiences [21, 22]. These instruments are based on existing patient-satisfaction questionnaires, interviews and focus groups. However, quality indicators for measuring patient centredness of cancer care based on evidence-based guidelines and opinions of patients do not exist.

This study reports the first step in improving patientcentred cancer care in which we have systematically developed a set of indicators to measure the patient centredness of cancer care. We used a practice test to assess both the feasibility of this set of indicators with regard to psychometric characteristics and the quality of patient-centred cancer care for patients with non-small cell lung cancer (NSCLC) in the Dutch eastern comprehensive cancer region.

\section{Materials and methods}

\section{Development of indicators}

The development of indicators started with a search for evidence-based guidelines regarding the management of patients with all types of cancer. We searched the two largest English-language national databases for evidencebased guidelines (UK: National Institute for Health and Clinical Excellence; USA: Agency for Healthcare Research and Quality) and the Dutch oncology database Oncoline (www.oncoline.nl; www.guideline.gov; www.nice.org.uk). All guidelines for the general management of patients with all types of cancer were included. Guidelines for specific aspects of care management for patients with cancer were excluded (e.g. pain management). One researcher extracted all the recommendations from the guidelines that had to do with organising care around the physical, social and emotional needs and the preferences of patients. We used a semi-structured method to interview 30 patients with head and neck cancer, as well as all seven patient representatives from the Dutch national association of patients with lung cancer. The interviewer read the recommendations aloud, and the patients and their representatives were asked to rate the recommendations on a nine-point Likert scale to determine their degree of importance for the patient centredness of care (a score of 1 meant 'not important at all' and 9 meant 'very important'). They were also given a chance to add new items. All recommendations with a mean score of 8 points or more were included in the final set. Domains were extracted from the guidelines and two researchers classified all the recommendations into the domains of patient centredness. Two researchers translated the recommendations into indicators, a process of defining numerators and denominators. A panel of four researchers judged the translation process from recommendation to indicator (Fig. 1).

\section{Questionnaire}

The indicators were reflected in a questionnaire for cancer patients. The questionnaire asked patients for their actual experiences with care and not for their satisfaction. We asked patients with NSCLC to rate their experiences regarding 56 aspects of patient-centred care on a four-point Likert scale $(1=$ not done; $2=$ done, but inadequately; $3=$ done adequately; $4=$ done excellently) or on a YES or NO scale. The indicators evaluated on a Likert scale were coded as dichotomous scores: adherence to the indicator 'yes' (score 1 or 2 ) or 'no' (score 3 or 4 ). These 56 aspects of care are part of one of the eight domains of patient-centred care, namely, access (e.g. 'Did you start therapy within 35 days of your first visit to the specialist'), follow-up ('Did you know which medicine to take at home?'), communication and respect ('Do you trust your specialist?'), involvement ('Were family and friends involved during care and follow-up?'), information ('Did you receive written information about treatment?'), coordination ('Did you know how to reach specialists?'), physical support ('Did you get support to 


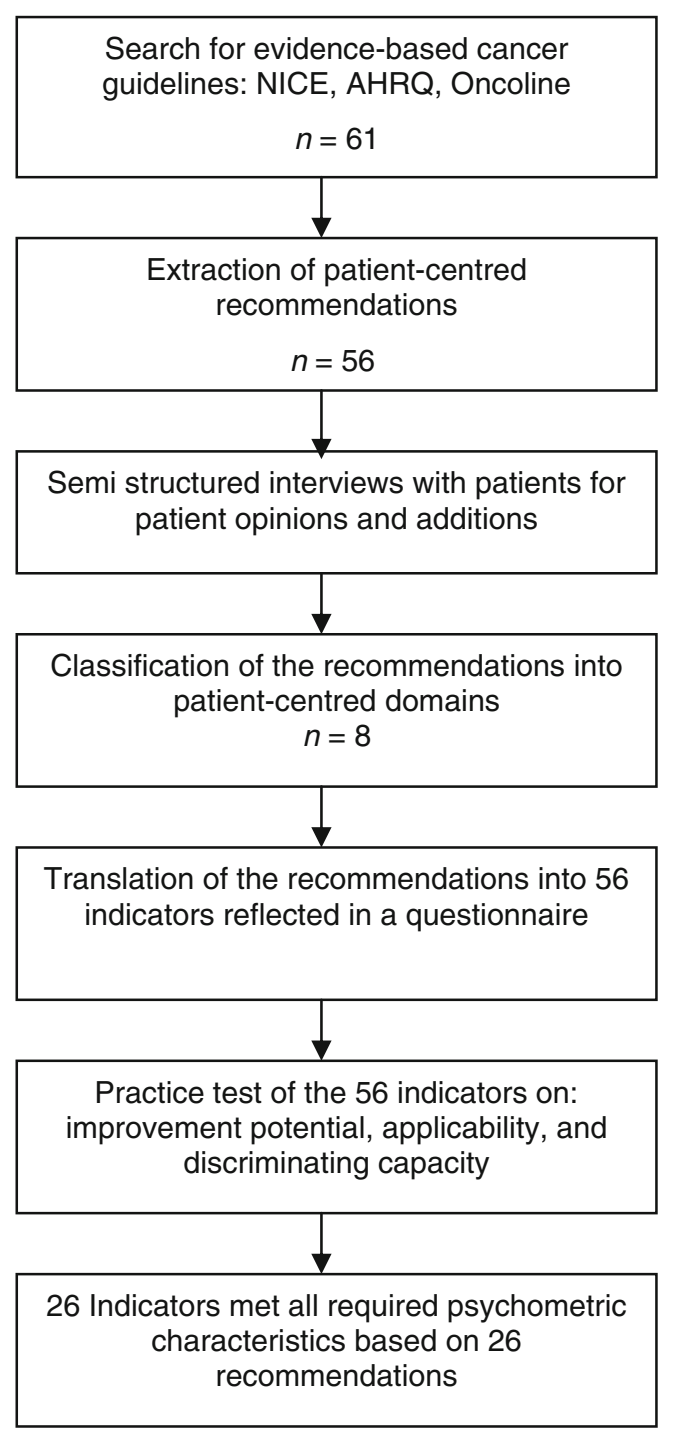

Fig. 1 Study design

control your pain?') and emotional and psychosocial support ('Did the specialist ask about fear and your mental state?').

Practice test

The questionnaire was tested in a group of 132 patients with NSCLC. This practice test took place in six hospitals in the Dutch eastern comprehensive cancer region (Table 1). The period patients were asked to evaluate was from the first visit until the beginning of treatment. After the ethics committee of the Radboud University Medical Centre in Nijmegen, The Netherlands approved the study, we included all consecutive patients newly diagnosed with NSCLC in the 6 months from September 2004 to February 2005 inclusive. The staff members of the Eastern Comprehensive Cancer Centre retrospectively included the patients by pathology diagnosis. Each hospital's pulmonologist checked the patient records to ensure that all questionnaire recipients were still alive. The researchers sent the questionnaires to the patients' homes, in a way that ensured patient anonymity, after the inclusion period had ended. The questionnaires were accompanied by a letter from each patient's own pulmonologist. A reminder was sent to each patient who had not replied after 2 weeks.

To test the feasibility of our set of indicators, we assessed the following psychometric characteristics: room for quality improvement, applicability, and discriminating capacity and reliability. Indicators must be capable of detecting improvements in the quality of care. If, for example, indicator performance is invariably high, there is little room for improvement. We considered that room for improvement was limited when the score for an indicator was $90 \%$ or more [31]. Applicability was measured as the proportion of patients to whom the indicator was applicable. Applicability was considered poor if this proportion was less than $75 \%[31,34]$. When the range between the lowest and highest hospital scores is broad (we assumed $20 \%$ or more), an indicator has discriminating potential and is sensitive in detecting differences.

Ultimately, we tested all the indicators that fulfilled the psychometric criteria for reliability regarding the eight domains of patient centredness by calculating Cronbach's alpha coefficients for the domains. A Cronbach's alpha score of 0.7 or more implies that the measures within one domain are reliably related to other measures included within the same domain [12].

\section{Results}

Development of indicators

We found 61 evidence-based oncology guidelines in the three databases, from which we extracted 56 recommendations.
Table 1 Descriptive characteristics of the six hospitals

\begin{tabular}{lcl}
\hline & Number & Percentage (range) \\
\hline Teaching hospital & 4 & 67 \\
Hospital beds, mean (range) & 630 & $(200-960)$ \\
Lung cancer patients (NSCLC) seen per year, mean (range) & 100 & $(30-160)$ \\
Availability of a multidisciplinary team for lung cancer & 2 & 33 \\
Specialised nurse with coordination tasks & 1 & 17 \\
\hline
\end{tabular}


Patients or their representatives who were interviewed $(n=37)$ found all the recommendations important (mean score of 8 or more), so we included all of them [10]. Adding patient opinions had added value concerning criteria for waiting times and information supply. The guidelines often recommended speeding up the diagnosis and starting treatment as soon as possible. However, they provided hardly any concrete information about acceptable waiting times. The criteria for waiting and throughput times in our study came from the patient interviews as answers to the question of acceptable waiting times. Furthermore, the patients added three specific information items, namely, 'information about the possible course of the disease', 'the possibility of a second opinion' and 'information about the treatment option of "no active therapy". The eight domains of patient centredness are access, follow-up, communication and respect, patient and family involvement, information, coordination, physical support and emotional and psychosocial support. The domains most often mentioned in the guidelines were 'follow-up' (38\%), 'emotional and psychosocial support' (34\%) and 'multidisciplinary patient care team' (30\%). The least mentioned domain was 'paramedical support, e.g. dietician' (10\%; Table 3). All the recommendations were translated into a set of 56 indicators (Fig. 1).

\section{Practice test}

\section{Study population}

During the study period of 6 months, a population of 276 patients with NSCLC were included. However, because many patients with NSCLC die within months after diagnosis, we were only able to send 132 of the 276 patients a questionnaire.

All patients received the questionnaire 2 to 6 months after their first visit to the pulmonologist. Seventy-six percent of the patients returned the questionnaire. The responders $(n=$ $100)$ and non-responders $(n=32)$ did not significantly differ in sex, age and disease stage (Table 2).

\section{Psychometric characteristics: room for improvement}

The least room for improvement was found within the domains 'communication and respect' (mean score of 95\% and all indicators in this domain scored $89 \%$ or more), followed by the domain 'patient and family involvement' (mean score of $84 \%$ and individual scores of $71 \%$ or more; Table 4) Most room for improvement was found within the domains 'physical support', 'emotional and psychosocial support' and 'information'. Patients did get physical support during the hospital stay $(80 \%)$, but hardly any at home (36\%), and only $58 \%$ of the patients felt that they had received enough support to control their physical complaints of pain, suffocation, nausea, weight loss, insomnia, tingling and blood coughs (Table 4). About one third of the patients stated that they were asked if they had psychological complaints or had problems with living conditions, but only $39 \%$ of the patients who needed support from caregivers who specialise in mental health actually got this care (Table 4). Regarding information, only $19 \%$ of the patients stated that they received enough information about all ten information items (Table 4). The information items mentioned most often were 'aim and follow-up of diagnostic procedures' and 'treatment options and pros and cons'. The items mentioned least were 'availability of emotional support', 'opportunity of contacting a companion in distress' and 'the possibility of a second opinion'. Overall, 44 of the 56 indicators (79\%) had an improvement potential of $10 \%$ or more (Fig. 2).

\section{Psychometric characteristics: applicability}

We found that ten of the 56 indicators were applicable to less than $75 \%$ of the population (Table 4). Low applicability scores were found for some indicators regarding oncology nurses, patients in need of specialised mental care who actually received this support, involvement of paramedical professionals and involvement of home care. Overall, 46 indicators had good applicability (Fig. 2).

\section{Psychometric characteristics: discriminating capacity}

Our study showed that 36 indicators had scores with a range of $20 \%$ or more between the highest and lowest scoring hospitals (Table 4). The largest ranges between the six hospitals were for the indicators "patients receive support from caregivers who specialise in mental health if needed' (the lowest hospital score was $0 \%$ and the highest
Table 2 Descriptive characteristics of the 132 patients

\begin{tabular}{lll}
\hline & Response $(n=100)[n(\%)]$ & Non-response $(n=32)[n(\%)]$ \\
\hline Mean age in years & 66 & 68 \\
Men & $65(66)$ & $19(60)$ \\
Disease stage IV & $23(24)$ & $9(32)$ \\
Other cancer 5 years or longer ago & $9(9)$ & $6(18)$ \\
\hline
\end{tabular}


Table 3 Patient-centred domains in 61 general oncology guidelines

\begin{tabular}{|c|c|c|c|c|c|c|c|c|}
\hline & \multicolumn{2}{|c|}{ Oncoline $(n=14)$} & \multicolumn{2}{|c|}{ AHRQ $(n=36)$} & \multicolumn{2}{|c|}{$\operatorname{NICE}(n=11)$} & \multicolumn{2}{|c|}{ Total $(n=61)$} \\
\hline & $n$ & $\%$ & $n$ & $\%$ & $n$ & $\%$ & $n$ & $\%$ \\
\hline 1. Access to care & 1 & 7 & 2 & 6 & 5 & 45 & 8 & 13 \\
\hline 2. Follow-up & 12 & 86 & 13 & 36 & 6 & 55 & 23 & 38 \\
\hline 3. Communication and respect & 2 & 14 & 6 & 17 & 2 & 18 & 10 & 16 \\
\hline 4. Patient and family involvement & 2 & 14 & 4 & 11 & 2 & 18 & 8 & 13 \\
\hline 5. Information & 4 & 29 & 5 & 14 & 6 & 55 & 15 & 25 \\
\hline \multicolumn{9}{|l|}{ 6. Coordination } \\
\hline Specialists/multidisciplinary patient care team & 4 & 29 & 5 & 14 & 9 & 82 & 18 & 30 \\
\hline Oncology nurse with case management tasks & 2 & 14 & 5 & 14 & 6 & 55 & 13 & 21 \\
\hline Paramedical support & 3 & 21 & & & 3 & 27 & 6 & 10 \\
\hline 7. Physical support (pain, nausea, etc.) & 3 & 21 & 4 & 11 & 5 & 50 & 12 & 20 \\
\hline 8. Emotional and psychosocial support & 9 & 64 & 6 & 17 & 6 & 55 & 21 & 34 \\
\hline
\end{tabular}

The table shows the number of times a patient-centred domain was mentioned in the guideline, e.g. recommendations on follow-up were mentioned in $38 \%$ of all guidelines (23 of 38 )

AHRQ Agency for Healthcare Research and Quality, NICE National Institute for Health and Clinical Excellence

was $100 \%$ ) and 'specialist asked patient about fear and mental state' (the lowest hospital score was $32 \%$ and the highest was $100 \%$ ).

\section{Psychometric characteristics: reliability}

The best indicators for quality improvement are those that have more that $10 \%$ room for improvement, good applicability ( $75 \%$ or more) and good discriminating capacities (at least $20 \%$ difference between lowest and highest scoring hospitals). In our study, 26 of the 56 indicators had good scores on all three psychometric characteristics (Fig. 2). They cover eight domains of patient centredness as shown in grey in Table 3. The recommendations on which these indicators are based are shown in Table 4. Seven of these eight domains had a Cronbach's alpha of 0.67 or more, and the reliability was acceptable. The domain 'coordination of specialists' had an alpha of 0.22 (Table 5).

\section{Discussion}

Patient centredness is an important principle for delivering high-quality integrated care. Before patient centredness can be improved, it must be assessed with a valid set of indicators. The development of a valid set of indicators for patient centredness that is applicable to all patients with cancer is an initial step towards improving the care. In our study, we developed 56 indicators for patient centredness covering eight domains of cancer care. There was considerable variation in the domains discussed in the guidelines. The indicators were evaluated in a practice test of the following psychometric characteristics: room for improvement, applicability and discriminating capacity and reliability. Twenty-six of the 56 indicators for patient-centred cancer care had good psychometric characteristics and were tested for reliability.

The eight domains of patient-centred cancer care correspond to patient-centred care dimensions that others mention (www.pickerinstitute.com) [28]. We recommend that specific domains for patient centredness always be addressed in clinical guidelines for the management of patients with cancer, such as, for example, the domains mentioned in this study. Although the literature shows that oncology guidelines have significantly higher scores for the consideration of patients' views than guidelines for other patient groups [6], we found a large variation within oncology literature covering patient-centred issues. The relatively few patient-centred recommendations in some guidelines may be due to the fact that patients are often not involved in guideline development. However, this is one of the key criteria for good clinical guidelines as proposed by the Appraisal of Guidelines Research and Evaluation collaboration [14]. We believe that involving patients in both guideline development and indicator development may improve patient centredness. In our study, involving patients in indicator development resulted in some additional points that would not otherwise have been noticed as information items and criteria for waiting and throughput times.

The literature provides only a few studies about indicator development $[26,27]$, and our study is the first to develop and test a general set of indicators for patient-centred cancer care. Our method of combining recommendations from 
Table 4 Scores and psychometric characteristics of the patient-centred cancer care indicators

Domains of patient-centred cancer care (total $n=100$ )
Score

$(\%)$
Room

$(\%)$
Applicability

$(\%)$
Range

$(\%)$

1. Access (mean score, $68 \%$ )

Waiting time first visit lung specialist $<5$ days

49

Waiting time start first treatment from first visit specialist $<35$ days ${ }^{\mathrm{a}}$

Waiting time diagnostic procedures from first visit specialist $<21$ days $^{\mathrm{a}}$

Waiting time general practitioner $<2$ days

2. Follow-up (mean score, $81 \%$ )

Home care knows about the patient's situation

Patient knows which activities are allowed at home

Patient knows which side effects to be aware of ${ }^{\mathrm{a}}$

Patient knows when to contact the primary care doctor or specialist $\mathrm{t}^{\mathrm{a}}$

Patient knows at discharge which medication to take and why

The primary care doctor knows about the patient's situation

Patient follow-up takes place on an agreed schedule

Specialist has enough time during consultations

Patient can reach the specialist between consultations

3. Communication and respect (mean score, 95\%)

Specialist showed interest in you as a person ${ }^{\mathrm{a}}$

Specialists talked to others as if you were not there

Nurses talked as if you were not there

Nurses showed interest in you as a person

Patient trusts in the specialists

Patient trusts the nurses

Patient feels respected during treatment

4. Patient and family involvement (mean score, $84 \%$ )

Nurses involved family and friends during care and follow-up

Specialists involved family and friends during treatment and follow-up ${ }^{\mathrm{a}}$

Specialists shared the decision making with the patient ${ }^{\mathrm{a}}$

Family and friends had opportunities to ask the specialists questions ${ }^{\mathrm{a}}$

Family and friends had opportunities to ask the nurses questions ${ }^{\mathrm{a}}$

Patient had the knowledge and support to make decisions

Patient had opportunities to ask questions ${ }^{\mathrm{a}}$

Specialists discussed aim and follow-up of the treatment with the patient

5. Information (mean score, $68 \%$ )

Patient received information on all ten information items ${ }^{\mathrm{a}}$ (see note under Table 5)

Patient received written information ${ }^{\mathrm{a}}$

Patient received clear answers from the nurses

Patient received contradictory information

Patient received clear answers from the specialists ${ }^{\mathrm{a}}$

6. Coordination (mean score, $71 \%$ )

Coordination: specialists (mean score, $87 \%$ )

Specialists involved knew patient's history

Patient knew how to reach specialists ${ }^{\mathrm{a}}$

Patient knew about being discussed in a multidisciplinary team of specialists $^{\mathrm{a}}$

Specialists involved took care of the coordination ${ }^{\mathrm{a}}$

Patient knew which specialist is his main contact person

Coordination: specialised nurse(s) (mean score, 55\%)

Oncology nurse was present during bad news consultation ${ }^{\mathrm{a}}$
42-56

40-80

50-89

82-100

14-80

57-86

55-100

57-100

83-100

83-100

87-100

93-100

89-100

67-100

91-100

91-100

86-100

91-100

86-100

91-100

61-100

73-100

67-100

60-100

76-100

82-100

76-100

87-100

$17-57$

64-86

83-100

85-100

77-100

75-94

65-100

67-100

87-100

100 
Table 4 (continued)

\begin{tabular}{|c|c|c|c|c|}
\hline Domains of patient-centred cancer care (total $n=100$ ) & $\begin{array}{l}\text { Score } \\
(\%)\end{array}$ & $\begin{array}{l}\text { Room for improvement } \\
(\%)\end{array}$ & $\begin{array}{l}\text { Applicability } \\
(\%)\end{array}$ & $\begin{array}{l}\text { Range } \\
(\%)\end{array}$ \\
\hline Existence of an oncology nurse was known by patient ${ }^{\mathrm{a}}$ & 53 & 47 & 93 & $33-86$ \\
\hline Patient knew how to reach oncology nurse ${ }^{a}$ & 53 & 47 & 100 & $46-86$ \\
\hline Oncology nurse knew patient's history & 61 & 39 & 29 & $38-100$ \\
\hline Oncology nurses took care of the coordination & 71 & 29 & 50 & $50-100$ \\
\hline \multicolumn{5}{|l|}{ Coordination: Paramedics (mean score, $70 \%$ ) } \\
\hline Patient knew how to reach paramedic professionals & 55 & 45 & 61 & $36-100$ \\
\hline Paramedic professionals involved knew patient's history & 76 & 24 & 62 & $53-100$ \\
\hline Paramedic professionals involved took care of the coordination & 80 & 20 & 43 & $50-100$ \\
\hline \multicolumn{5}{|l|}{ 7. Physical support (mean score, $58 \%$ ) } \\
\hline Patient got support for daily activities at home & 36 & 74 & 72 & $10-40$ \\
\hline Patient got support to control physical complaints ${ }^{\mathrm{a}}$ & 58 & 42 & 89 & $25-78$ \\
\hline Patient got support for daily activities in the hospital & 80 & 20 & 88 & $73-92$ \\
\hline \multicolumn{5}{|l|}{ 8. Emotional and psychosocial support (mean score, $46 \%$ ) } \\
\hline Patient was offered contact with companion in distress ${ }^{\mathrm{a}}$ & 13 & 87 & 100 & $0-43$ \\
\hline Patient was asked whether he had psychological complaints ${ }^{\mathrm{a}}$ & 34 & 66 & 83 & $18-60$ \\
\hline Patient was asked whether he had problems with living conditions ${ }^{a}$ & 36 & 64 & 85 & $23-60$ \\
\hline $\begin{array}{l}\text { Patient received support from specialised caregivers in mental health if } \\
\text { needed }\end{array}$ & 39 & 61 & 28 & $0-100$ \\
\hline Specialist asked patient about fear and mental state $\mathrm{a}^{\mathrm{a}}$ & 52 & 48 & 88 & $32-100$ \\
\hline Patient received emotional support from nurses if needed & 74 & 26 & 65 & $63-100$ \\
\hline Patient received emotional support from specialists if needed & 74 & 26 & 60 & $46-100$ \\
\hline
\end{tabular}

${ }^{a}$ Indicator that met all psychometric characteristics

guidelines with patients' opinions led to a large set of indicators. The usefulness of a quality indicator depends on various psychometric characteristics, and we decided to test our set of indicators on some psychometric characteristics

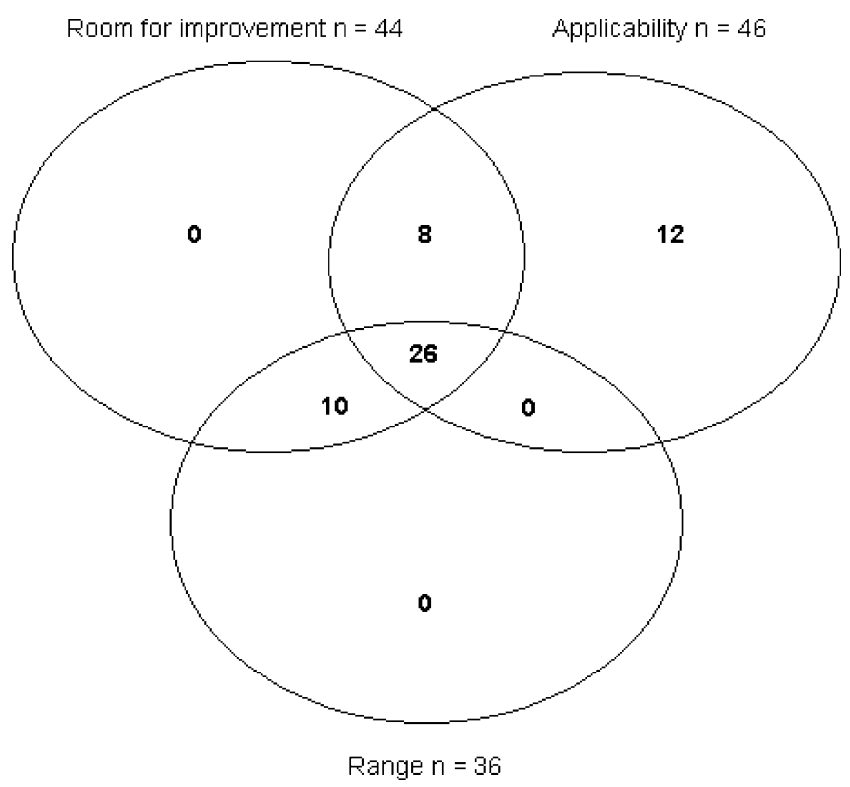

Fig. 2 The 56 indicators and their psychometric characteristics to come up with a core set. There are not many studies on psychometric characteristics of indicators or norms for 'good characteristics'. Our choice of psychometric criteria and norms was based on the literature and our experiences in other studies and was therefore disputable. We chose 'room for improvement' because indicators that invariably have high scores provide little room for improvement and are therefore less suited for quality improvement. Other criteria for good indicators are 'applicable to a large part of the population' and 'high variation between hospitals'. We did not test the indicator set for criterion validity because a golden standard for patient centredness is lacking.

Further research should test the original set of 56 indicators on other populations of cancer patients to provide additional evidence for the applicability of these indicators.

The scores for the criterion 'room for improvement' shows many improvement opportunities for patients with NSCLC. In line with other studies, our practice test regarding patients with NSCLC showed that patients reported poor management and evaluation of their physical symptoms and psychosocial problems, and they were not fully informed $[23,30,35]$. Cancer is a serious and life-threatening illness, especially for patients with NSCLC, because the disease is most often incurable [19]. The impact of lung cancer and its symptoms on the patient's psychological, social 
Table 5 Recommendations for patient-centred cancer care tested on patient with non-small cell lung cancer

Access

Patient receives all necessary diagnostic procedures within 21 days after his first visit to the specialist

Patient starts his treatment within 35 days after his first visit to the specialist

Follow-up

Patient knows which side effects to be aware of at home

Patient knows which activities are allowed at home

Patient knows when to contact the primary care doctor or specialist

Communication and respect

Specialist shows interest in the patient as a person

Patient and family involvement

Nurses involve family and friends during care and follow-up

Specialists involve family and friends during treatment and follow-up

Specialists share the decision making with the patient

Family and friends have opportunities to ask the specialists questions

Family and friends have opportunities to ask the nurses questions

Patient has opportunities to ask questions

Information

Patient receives information on all ten items if applicable ${ }^{a}$

Patient receives written information on all applicable items ${ }^{\mathrm{a}}$

Patient receives clear answers from the specialists

Coordination: specialists

Patient knows how to reach the specialists

Patient knows being discussed in a multidisciplinary team of specialists

The specialists involved take care of the coordination

Coordination: oncology nurse(s)

An oncology nurse was present during the bad news consultation

Patient knows that nurses specialising in oncology exist

Patient knows how to reach the oncology nurse

Physical support

Patient gets support to control physical complaints such as pain, suffocation, nausea, blood coughs, tingling, weight loss and insomnia

Emotional support

Patient is offered contact with a companion in distress

Patient is asked about psychological complaints

Patient is asked whether has problems with living conditions

Specialist asks the patient about possible fear and mental state

a Aim and follow-up of diagnostic procedures, treatment options and pros and cons, treatment option 'no active therapy', estimation of possible course of illness, possible loss of weight during treatment and the importance of eating well, options for pain medication, options for anaesthesia in case of operation, opportunities for emotional support, companion in distress, possibility of a second opinion

and physical state should be identified early, and patients should be referred to the appropriate specialist for further assessment, if needed. The literature shows that screening lists for quality-of-life issues could be helpful [11] and that structured follow-up by nurses can improve psychosocial functioning [29]. Failure to provide sufficient information about disease-related issues is the most frequent source of patient dissatisfaction [13]. A good supply of information has positive effects on patient satisfaction and quality of life [16]. Suggested interventions in the literature to make sure that patients are informed properly include printed material [9], consultation preparation packages [7] and audiocassettes of consultations[5].

There are some good examples of instruments that measure patient satisfaction and patient experiences [3, 4, $21,22]$, but they are not based on clinical guidelines. Our focus on the evaluation of clinical guidelines can be seen as a complement to other measures to obtain patients' assessments of the quality of health care. Our evaluation shows an original and innovative approach to the practice test and 
development of indicators for patient centredness in cancer care. Our set of indicators can be useful to anyone interested in measuring the degree of patient centredness of cancer care. The recommendations on which the indicators are based are not part of all general oncology guidelines. The recommendations for patient centredness on which the indicators are based could be considered for incorporation into general oncology guidelines.

The indicators of patient centredness were measured by means of patient questionnaires. Obviously, the subjective opinion of patients may have biased the outcome to some degree. The outcome of treatment and the stage of the disease may have had a negative impact on the recall of initial conversations with the doctor. To deal with this, we asked patients for their actual experiences of clinical care, as suggested in the literature, and not for their satisfaction with care provided [10]. It should be noted that the literature is contradictory about the influence of patient characteristics on their assessments of care [17, 33].

\section{Conclusion}

In conclusion, the development of a valid set of indicators for the patient centredness of cancer care is an initial step towards improvement. Indicators can be based on recommendations from guidelines, but adding patients' opinions leads to a more complete picture of patient centredness. In this study, we have developed and tested a general set of indicators for patient centredness. Our practice test showed that many of them appeared to be useful for patients with NSCLC and that there are many improvement opportunities. Our set of indicators may also be useful for future quality assessments for other patients with cancers or chronic diseases. Therefore, the indicators developed in this study should be verified in a practice test in other patient groups to see which indicators also apply to them.

Acknowledgements We thank our contacts at the six participating hospitals for their cooperation: M. van der Drift, Radboud University Hospital, Nijmegen; H. Smit, Rijnstate Hospital, Arnhem; R. Termeer, Canisius Wilhelmina Hospital, Nijmegen; R. Bunnik, Pantein Hospital, Boxmeer; M. Oudijk, Gelders Valley Hospital, Ede and G. Bosman, Slingeland Hospital, Doetinchem.

\section{Conflict of interest No conflicts of interest}

Open Access This article is distributed under the terms of the Creative Commons Attribution Noncommercial License which permits any noncommercial use, distribution, and reproduction in any medium, provided the original author(s) and source are credited.

\section{References}

1. Allgar VL, Neal RD (2005) Delays in the diagnosis of six cancers: analysis of data from the National Survey of NHS Patients: cancer. Br J Cancer 92:1959-1970. doi:10.1038/sj.bjc.6602587

2. Boyle P, Ferlay J (2004) Cancer incidence and mortality in Europe. Ann Oncol 16:481-488. doi:10.1093/annonc/mdi098

3. Bredart A, Mignot V, Rousseau A, Dolbeault S, Beauloye N, Adam V (2004) Validation of the EORTC QLQ-SAT32 cancer inpatient satisfaction questionnaire by self- versus interviewassessment comparison. Patient Educ Couns 54:207-2012. doi:10.1016/S0738-3991(03)00210-6

4. Bredart A, Bottomley A, Blazeby JM, Conroy T, Coens C, D'Haese S (2005) An international prospective study of the EORTC cancer in-patient satisfaction with care measure (EORTC IN-PATSAT32). Eur J Cancer 41:2120-2131. doi:10.1016/j.ejca.2005.04.041

5. Bruera E, Pituskin E, Calder K, Neumann CM, Hanson J (1999) The addition of an audiocassette recording of a consultation to written recommendations for patients with advanced cancer: a randomized, controlled trial. Cancer 86:2420-2425. doi:10.1002/(SICI)10970142(19991201)86:11<2420::AID-CNCR33>3.0.CO;2-O

6. Burgers JS, Fervers B, Haugh M, Brouwers M, Browman G, Philip T (2004) International assessment of the quality of clinical practice guidelines in oncology using the appraisal of guidelines and research and evaluation instrument. J Clin Oncol 22:2000 2007. doi: $10.1200 / J C O .2004 .06 .157$

7. Butow P, Devine R, Boyer M, Pendlebury S, Jackson M, Tattersall MH (2004) Cancer consultation preparation package: changing patients but not physicians is not enough. J Clin Oncol 22:44014409. doi:10.1200/JCO.2004.66.155

8. Campbell SM, Braspenning J, Hutchinson A, Marshall MN (2003) Research methods used in developing and applying quality indicators in primary care. BMJ 326:816-819. doi:10.1136/ bmj.326.7393.816

9. Chan Y, Irish JC, Wood SJ, Rotstein LE, Brown DH, Gullane PJ (2002) Patient education and informed consent in head and neck surgery. Arch Otolaryngol Head Neck Surg 128:1269-1274

10. Coulter A (2006) Can patients assess the quality of health care? BMJ 333:1-2. doi:10.1136/bmj.333.7557.1

11. Detmar SB, Muller MJ, Schornagel JH, Wever LD, Aaronson NK (2002) Health-related quality-of-life assessments and patientphysician communication: a randomized controlled trial. JAMA 288:3027-3034. doi:10.1001/jama.288.23.3027

12. DeVillis R (1991) Scale development. Applications and theory. Sage, Newbury Park, CA

13. Grol R, Wensing M, Mainz J, Jung HP, Ferreira P, Hearnshaw $H$ (2000) Patients in Europe evaluate general practice care: an international comparison. Br J Gen Pract 50:882-887

14. Grol R, Cluzeau FA, Burgers JS (2003) Clinical practice guidelines: towards better quality guidelines and increased international collaboration. Br J Cancer 89(Suppl):S4-S8. doi:10.1038/sj. bjc. 6601077

15. Grol R, Wensing M, Eccles M (2005) Improving patient care; the implementation of change in clinical practice. Elsevier, London

16. Haggmark C, Bohman L, Ilmoni-Brandt K, Naslund I, Sjoden PO, Nilsson B (2001) Effects of information supply on satisfaction with information and quality of life in cancer patients receiving curative radiation therapy. Patient Educ Couns 45:173-179. doi:10.1016/S0738-3991(01)00116-1

17. Hargraves JL, Wilson IB, Zaslavsky A, James C, Walker JD, Rogers G (2001) Adjusting for patient characteristics when analyzing reports from patients about hospital care. Med Care 39:635-641. doi:10.1097/00005650-200106000-00011

18. Hermens RP, Ouwens MM, Vonk-Okhuijsen SY, van der Wel Y, Tjan-Heijnen VC, van den Broek LD (2006) Development of 
quality indicators for diagnosis and treatment of patients with nonsmall cell lung cancer: a first step toward implementing a multidisciplinary, evidence-based guideline. Lung Cancer 54:117-124. doi:10.1016/j.lungcan.2006.07.001

19. Janssen-Heijnen ML, Coebergh JW (2003) The changing epidemiology of lung cancer in Europe. Lung Cancer 41:245-258. doi:10.1016/S0169-5002(03)00230-7

20. Jenkins V, Fallowfield L, Saul J (2001) Information needs of patients with cancer: results from a large study in UK cancer centres. Br J Cancer 5(84):48-51. doi:10.1054/bjoc.2000. 1573

21. Jenkinson C, Coulter A, Bruster S (2002) The Picker Patient Experience Questionnaire: development and validation using data from in-patient surveys in five countries. Int J Qual Health Care 14:353-358. doi:10.1093/intqhe/14.5.353

22. Jenkinson C, Coulter A, Bruster S, Richards N, Chandola T (2002) Patients' experiences and satisfaction with health care: results of a questionnaire study of specific aspects of care. Qual Saf Health Care 11:335-339. doi:10.1136/qhc.11.4.335

23. Kash KM, Mago R, Kunkel EJ (2005) Psychosocial oncology: supportive care for the cancer patient. Semin Oncol 32:211-218. doi:10.1053/j.seminoncol.2004.11.011

24. Kerr D, Bevan H, Gowland B, Penny J, Berwick D (2002) Redesigning cancer care. BMJ 324:164-166. doi:10.1136/bmj. 324.7330 .164

25. Lewin SA, Zwarenstein M (2001) Interventions for providers to promote a patient-centred approach in clinical consultations. Cochrane Database Syst Rev 4:CD003267

26. Malin JL, Asch SM, Kerr EA, McGlynn EA (2000) Evaluating the quality of cancer care: development of cancer quality indicators for a global quality assessment tool. Cancer 88:701707. doi:10.1002/(SICI)1097-0142(20000201)88:3<701::AIDCNCR29>3.0.CO;2-V

27. Malin JL, Schneider EC, Epstein AM, Adams J, Emanuel EJ, Kahn KL (2006) Results of the National Initiative for Cancer Care
Quality: how can we improve the quality of cancer care in the United States? J Clin Oncol 24:626-634. doi:10.1200/JCO. 2005.03.3365

28. Mead N, Bower P (2000) Patient-centredness: a conceptual framework and review of the empirical literature. Soc Sci Med 51:1087-1110. doi:10.1016/S0277-9536(00)00098-8

29. Moore S, Corner J, Haviland J, Wells M, Salmon E, Normand C (2002) Nurse led follow up and conventional medical follow up in management of patients with lung cancer: randomised trial. BMJ 325:1145. doi:10.1136/bmj.325.7373.1145

30. Oskay-Ozcelik G, Lehmacher W, Konsgen D, Christ H, Kaufmann M, Lichtenegger W (2007) Breast cancer patients' expectations in respect of the physician-patient relationship and treatment management results of a survey of 617 patients. Ann Oncol 18:479484. doi:10.1093/annonc/mdl456

31. Ouwens MM, Marres HA, Hermens RR, Hulscher MM, van den Hoogen FJ, Grol RP (2007) Quality of integrated care for patients with head and neck cancer: development and measurement of clinical indicators. Head Neck 29:378-386. doi:10.1002/hed.20532

32. Piro L, Doctor J (1998) Managed oncology care: the disease management model. Cancer 82(10 Suppl):2068-2075

33. Sandoval GA, Brown AD, Sullivan T, Green E (2006) Factors that influence cancer patients' overall perceptions of the quality of care. Int J Qual Health Care 18:266-274. doi:10.1093/intqhe/mzl014

34. Schouten JA, Hulscher ME, Wollersheim H, Braspennning J, Kullberg BJ, van der Meer JW (2005) Quality of antibiotic use for lower respiratory tract infections at hospitals: (how) can we measure it? Clin Infect Dis 41:450-460. doi:10.1086/431983

35. Shilling V, Jenkins V, Fallowfield L (2003) Factors affecting patient and clinician satisfaction with the clinical consultation: can communication skills training for clinicians improve satisfaction? Psychooncology 12:599-611. doi:10.1002/pon.731

36. Wagner EH (2002) Care for chronic diseases. BMJ 325:913-914. doi:10.1136/bmj.325.7370.913 